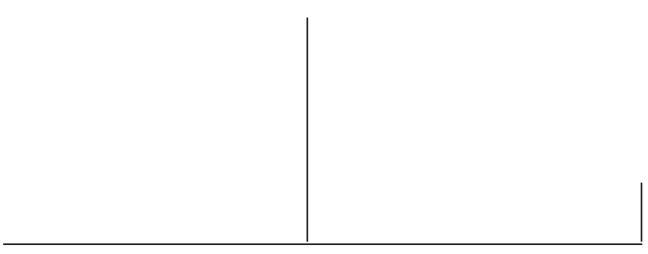

Rev. Latinoam. Psicopat. Fund., X, 3, 517-525

\title{
Primitivo e loucura, ou o inconsciente e a psicopatologia segundo Arthur Ramos
}

\author{
Mário Eduardo Costa Pereira \\ Guilherme Gutman
}

O psiquiatra brasileiro Arthur Ramos dá continuidade à tradição de uma abordagem antropológica e cultural dos fenômenos psicopatológicos iniciada por Raimundo Nina Rodrigues. Na primeira metade do século XX, Ramos estuda o fenômeno da loucura através de uma interlocução com a psicanálise e com a antropologia. Sua contribuição situa-se além do referencial estritamente psicopatológico, permitindo, também, uma interrogação fecunda sobre os processos de subjetivação próprios aos contextos culturais brasileiros, sobretudo o dos pobres e o dos negros.

Palavras-chave: Psicopatologia, loucura, psicanálise, antropologia, cultura 


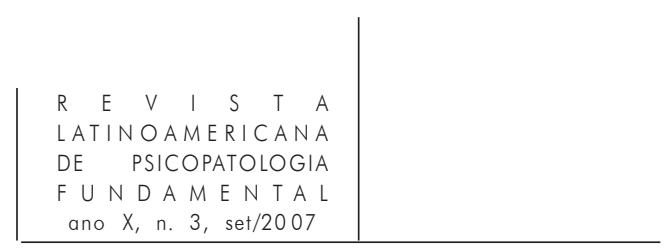

Discípulo intelectual de Raimundo Nina Rodrigues (1862-1906) e autoproclamado continuador de várias de suas teses, o psiquiatra e educador Arthur Ramos foi autor, na primeira metade do século XX, de uma formidável obra teórica no campo da psicopatologia, interrogando não apenas seus fundamentos, como também suas especificidades face à realidade brasileira de seu tempo. Promovendo um intenso debate entre as teses freudianas, a antropologia e as teorias psicopatológicas então vigentes na psiquiatria, esforçou-se especialmente em elucidar as relações entre, de um lado, a psicologia pessoal e a instalação de perturbações mentais; e, de outro, a constituição dos sujeitos no interior das culturas e das tradições históricas dos povos.

Arthur Ramos de Araújo Pereira nasceu em 1903, na cidade de Pilar, no interior do Estado de Alagoas. Em 1921 ingressa na Faculdade de Medicina da Bahia. Possuidor de uma vasta erudição, o jovem estudante surpreende o mundo acadêmico pelo brilhantismo de sua dissertação de conclusão de curso, defendida em 1926 e intitulada "Primitivo e loucura". O texto foi saudado primeiro pela imprensa baiana e alagoana, merecendo posteriormente comentários elogiosos de grandes nomes da psicopatologia e da psiquiatria como Juliano Moreira e Henrique Roxo, no Brasil; no estrangeiro destacaram-se as observações de Lucien LévyBruhl e Eugen Bleuler. Ramos fez ainda chegar um exemplar às mãos de Freud, mas como este tivesse respondido que não conseguia lê-la, posto que não falava o português, o brasileiro terminou por encaminhar-lhe uma versão traduzida que mereceu do pai da psicanálise o seguinte comentário, efetivado através de um cartão:

Ilustre e caro colega dr. Arthur Ramos. Acho as suas conclusões com as referências feitas ao seu trabalho, muito interessantes e documentadas exaustivamente, podendo ser o seu trabalho incluíd dentro dos domínios dos estudos psicanalíticos. Afetivamente. Freud. (Apud, Menezes, 2002, p. 56)

De sua leitura da obra de Nina Rodrigues, Arthur Ramos fez brotar o interesse pelo estudo da antropologia, sobretudo pela investigação da realidade cultural do povo brasileiro, em particular pela cultura negra, pelas religiões afrobrasileiras e pelas populações pobres dos morros cariocas, com suas práticas místicas e religiosas. Lançou-se ao contato direto com essas realidades e seus protagonistas, produzindo uma rica obra etnográfica e teórica. Seu propósito era, sobretudo, refletir sobre as condições culturais concretas do povo brasileiro, de modo a produzir um referencial teórico que servisse de substrato para 


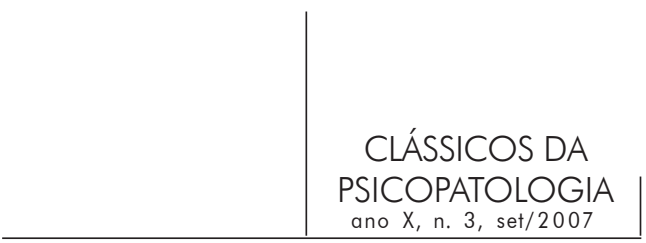

intervenções políticas, higienistas e educacionais efetivas no sentido de transformar os graves problemas sociais do país. Seu conhecimento da realidade cultural das fatias mais desfavorecidas da população brasileira não era, pois, apenas livresca e abstrata, mas fundava-se igualmente no contato direto com as comunidades marginalizadas, em geral deixadas sem voz ou reconhecimento.

Em um momento histórico em que o pensamento antropológico hegemônico no Brasil ainda se sustentava sobre a crença da superioridade inata da raça branca sobre as demais, Arthur Ramos propunha que as diferenças entre os grupos éticos deviam-se sobretudo a condições históricas e políticas particulares a cada um deles. O psiquiatra alagoano, mesmo assim, considerava os padrões culturais observados entre os brancos ocidentais como mais evoluídos que os demais, os quais deveriam ser auxiliados a superarem seu "atraso cultural", aproximando-os da proposta civilizatória européia (cf. Gutman, 2007).

É importante notar que mesmo na obra de seu predecessor confesso - Nina Rodrigues - havia tais elementos teóricos que Ramos não teve dificuldade em isolar como idéias racistas "cientificamente ultrapassadas". Assim, um modo de descrever o seu projeto se faria pela revisão do empreendimento iniciado pelo "sábio baiano", com vistas a uma nova elaboração do sonho de um Brasil como nação viável, embora com características étnicas e culturais próprias.

Aos trinta anos de idade, transfere-se para o Rio de Janeiro, na época Capital Federal, onde assumiria, a convite do educador, e então secretário da educação Anísio Teixeira, a chefia do Serviço de Ortofrenia e Higiene Mental do Instituto de Pesquisas Educacionais. Naquele contexto, e em mais uma evidência do quanto, em Ramos, a teoria andou sempre ao lado da ação, buscou colocar em prática "um projeto educacional que privilegiava o estudo de crianças escolarizadas com o objetivo de classificá-las segundo seu potencial intelectual e aptidão, visando tratar aquelas que apresentassem problemas de aprendizagem" (Sircilli, 2005, p. 186). Para identificar e compreender tais situações problemáticas, Arthur Ramos propunha o recurso à psicanálise, no sentido de obter, através dela, uma visão mais ampla da dinâmica sociopsicofamiliar em jogo em tais casos.

Ramos falece precocemente em 1949, em Paris, onde atuava no posto de chefe do departamento de ciências sócias da UNESCO. Nesse breve período de vida, deixa publicada uma obra na qual examina as condições das religiões afrobrasileiras servindo-se de seu rico material etnográfico, bem com da interlocução constante com a psicanálise e com a antropologia. Contribui, enfim, com atos e palavras - numerosas e maduras para quem viveu apenas 46 anos - para o tema principal da pauta nacional dos anos 1930 e 1940: pensar o Brasil como país com as suas especificidades e seus desafios.

Entre seus trabalhos mais relevantes encontram-se os livros: O negro brasileiro: etnografia religiosa e psicanálise (1934), O folclore negro no Brasil: 


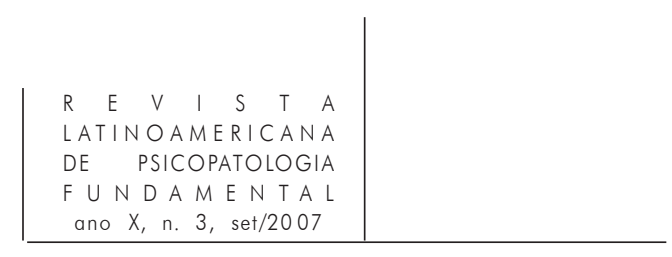

demopsicologia e psicanálise (1935), Introdução à psicologia social (1936), As culturas negras no novo mundo (1937), A criança problema (1939), Introdução à antropologia brasileira (1943) e, encabeçando cronologicamente a lista, sua tese de Medicina, intitulada Primitivo e loucura (1926).

O presente número da Revista Latinoamericana de Psicopatologia Fundamental reproduz o capítulo inicial de Primitivo e loucura, trabalho que constitui um verdadeiro clássico da psicopatologia brasileira.

Nota-se, já nesse escrito de juventude, seu interesse central e refinado pela psicanálise, a qual lhe serve de instrumento para teorizar as relações entre a tradição cultural dos povos e os eventos mentais singulares, em especial no campo da psicopatologia. Apoiado nas teses antropológicas de Lévy-Brühl e na teoria atavista de Tanzi, Arthur Ramos considerava que os fenômenos psicóticos consistiriam em expressões mórbidas do primitivo sufocado em cada sujeito e, para além do sujeito, da própria cultura, tal como Freud o proporia em seus estudos sobre as relações entre o inconsciente e a história das civilizações.

A dissertação de Artur Ramos, já em seu início, assume a posição explicitada por Augusto Comte, segundo a qual "o retrato psicológico do 'homem', [deve ser] explicado pela humanidade e não esta por aquele" (p. 4). Trata-se, portanto, de um plano de trabalho no qual se recorre à antropologia e à etnologia em direção ao esclarecimento das questões oriundas do campo da psicologia.

Todavia, sua concepção antropológica se constitui em boa medida numa crítica à visão hegemônica da época de seus antecessores e mesmo de alguns contemporâneos, na qual se concebia a racionalidade e a complexidade cultural da Europa Ocidental como uma espécie de ápice do desenvolvimento da civilização humana. Em relação ao suposto ápice cultural, as demais sociedades, avaliadas como em estágios anteriores e menos sofisticados do que a sua "prima rica" européia, deveriam referir-se como modelo.

Em sua abordagem, Arthur Ramos propõe inúmeras analogias e concordâncias entre "as funções mentais dos primitivos e os quadros psiquiátricos, bem como", continua ele, "múltiplos são os pontos de contato entre o primitivo, o louco, o sonho e a arte". Neste ponto, a sua posição é bem próxima da de outros psiquiatras que se propuseram, então, a pensar as relações entre o primitivismo, a loucura a arte e o mundo infantil. Entre estes, vale a menção a Osório César (1895-1979), psiquiatra paraibano que estudou "as manifestações artísticas dos alienados" (cf. Dalgalarrondo et al., 2007).

A noção de "Primitivo" à qual Ramos recorre, é aquela estabelecida por L. Lévy-Brühl; esse termo faria referência "às sociedades mais simples que conhecemos". Recorda, ainda, que desde a Antigüidade têm sido estudadas as relações entre sonho e loucura. Mesmo a pesquisa psiquiátrica, com trabalhos como os de Ball, Baillarger e Moreau de Tours já indicavam a pertinência de tal aproximação. 


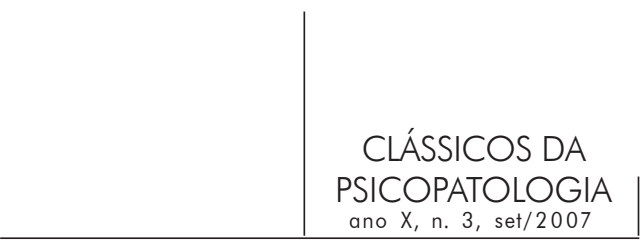

É assim que, segundo Arthur Ramos, os etnólogos já haviam apontado, antes mesmo de Freud, as relações entre o pensamento primitivo e a alienação mental.

Uma grande referência de Arthur Ramos no âmbito da psicopatologia são algumas das idéias da escola italiana de psiquiatria; entre elas as de Eugenio Tanzi, que propunha o estudo do folclore e da "inteligência primitiva" como formas de elucidação de "inteligências doentes ou monstruosas". Na continuidade das proposições de Tanzi, que aproximam atavismo e paranóia, Lombroso estabeleceu analogias entre "o delinqüente, o epiléptico de um lado, e o homem primitivo do outro" (ver p. 16). Ao reconhecer a sua filiação a tais idéias, Ramos revela a sua face menos aprovável. É que, segundo certos parâmetros atuais da pesquisa em psicopatologia, Tanzi, Lombroso e Nina Rodrigues seriam colocados, talvez um tanto apressadamente, lado a lado. Ramos integrou a Liga Brasileira de Higiene Mental e, como foi exposto acima, chegou a chefiar na então Capital Federal um serviço infantil de inspiração francamente higienista. Cabe a todo aquele que retorna às raízes históricas da psiquiatria no Brasil, saber separar o joio do trigo, reconhecendo nas contribuições de Ramos, aquilo que elas têm de interessante.

Freud, acompanhado de Lévy-Brühl, talvez sejam as maiores influências teóricas de Ramos, supondo que Nina Rodrigues foi mais que uma influência, tendo sido, na verdade, algo como um totem, a quem ele freqüentemente faz sinais de reverência. Freud é saudado por seus esforços em estudar minuciosamente "o desenvolvimento cultural na criança e na raça". A interpretação do fenômeno onírico como uma espécie de língua arcaica que subsiste no inconsciente da humanidade. Em "Totem e tabu" (1913), lembra Arthur Ramos, Freud realiza a aproximação entre o neurótico e o primitivo, a criança e o artista, e que os fantasmas primitivos exprimem, em última instância, o patrimônio cultural filogenético, segundo uma perspectiva muito próxima ao atavismo de Tanzi.

Apesar do elogio feito à psicanálise por seus esforços em demonstrar a origem ancestral e filogenética dos símbolos, Arthur Ramos a critica por suas visões reducionistas e cada vez mais complexas da sexualidade. O "pecado mortal" dessa disciplina teria sido a aplicação das teorias sobre o psiquismo individual como forma de elucidação da psicologia do primitivo, e não contrário.

Bleuler e Jung teriam se emancipado de tal desvio, concebendo um nível próprio, mais geral e mais básico ao primitivo. Segundo o ponto de vista freudiano, descobrimos no pensamento esquizofrênico analogias com os elementos oníricos, assim como concebemos aproximações entre certas produções da mente primitiva e certos sintomas neuróticos. Mas com o auxílio da "escola de Zurich", bem como com a presença de vários outros nomes entre seguidores e dissidentes das idéias de Freud - Adler, Stekel, Ferenczi, Rank, Abraham - Ramos vai construindo uma concepção psicanalítica meio antropofágica, bem ao modo modernista, do que seja "primitivismo". O funcionamento mental do selvagem, tal como aquele 


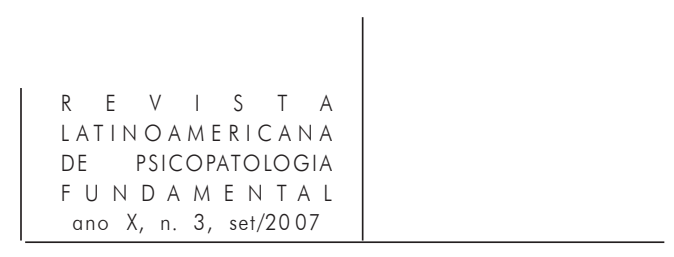

observado na loucura, "não conhece o limite de demarcação entre ser eu e a realidade". A paranóia e a esquizofrenia apresentariam analogias evidentes com a feitiçaria e o animismo, o que referendaria, segundo Arthur Ramos, a hipótese de que, em última instância, os fenômenos psicóticos constituem perturbações mórbidas nas quais retornariam tendências ancestrais primitivas, ilógicas e animistas.

É com essa visão ao mesmo tempo entusiasta, crítica, aglutinadora e voraz em relação às contribuições da psicanálise para a compreensão das relações entre história, cultura e psicopatologia, que Arthur Ramos viria a construir um de seus conceitos mais importantes e fecundos: o de "inconsciente folclórico". Segundo a proposição de Ramos, tal noção remeteria a uma estrutura arcaica indiferenciada, presente de forma bruta no homem "primitivo" e apenas sufocada no "civilizado", a qual emergiria neste em condições psicopatológicas ou, mesmo, como intrusões na vida social rotineira dos indivíduos e das coletividades. Consistiria na expressão mesma do atavismo psíquico imanente à cultura e cuja ancestralidade é transmitida filogeneticamente através das gerações. Dessa forma, mesmo o homem branco, supostamente civilizado, traria em si, de forma latente, "sentimentos de angústia e medo", além de formas primitivas de racionalidade e de pensamento, marcadas pelo animismo, pensamento mágico e paixões exacerbadas. Em um trecho do livro $O$ folclore do negro do Brasil, Ramos expõe a revelação dessa ancestralidade em suas expressões pitorescas e alegóricas. Escreve ele:

(No carnaval) todo um mundo de sentimentos, de crenças e de desejos, não tolerados na vida comum, despertam de um trabalho surdo de recalques contínuos. O carnaval é uma visão espectral da "cultura" de um grupo humano. Os civilizados explodem a sua vida instintiva reprimida. Mas o primitivo apenas se mostra na sua espontaneidade de origem. É o caso da Praça Onze, conglomerado de todo um inconsciente ancestral. (...).

É uma fantasmagoria. Num tempo absolutamente restrito, assistimos à recapitulação de toda uma vida coletiva. Instituições que se fragmentam, se esboroam e se diluem. Os seus remanescentes são recolhidos pela Praça Onze. A Praça Onze é uma grande trituradora, mó gigantesca, que elabora o material inconsciente, e prepara-o para a sua entrada na "civilização". (Ramos, 1935, p. 257)

Como bem propõe Menezes (2002), Arthur Ramos "apontou para a divisão artificial [que separa] inconsciente individual, interpsíquico ou ancestral". Encontrou inspiração para a denúncia dessa artificialidade sobretudo no conceito junguiano de "inconsciente coletivo" (überbewusst), que chama de “"superinconsciente', o depositário de todos os símbolos legados pelas gerações remotas, verdadeiras 'imagens arcaicas', tais os símbolos dos deuses, dos demônios etc., que dormem nos porões recônditos da alma da espécie” (p. 87). 


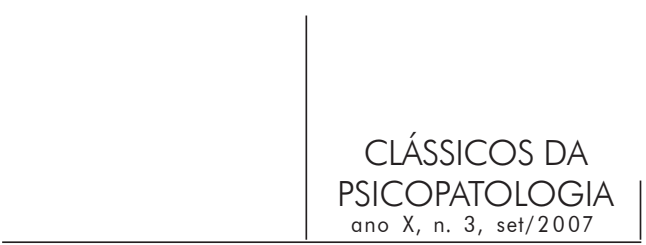

Em recapitulação, temos que $\mathrm{A}$. Ramos chegou à concepção de "inconsciente folclórico" pela combinação de influências teóricas heterogêneas. De "etnólogos e folcloristas", retira a idéia de que "além da alma individual, há um espírito objetivo, uma alma étnica que emana da massa gregária, e constituída por um complexo de elementos que sobrevive no folclore" (p. 84). De Lévy-Brühl, a da "persistência entre as classes civilizadas, das representações coletivas, de elementos pré-lógicos que podem coexistir com elementos lógicos" (p. 85). De Freud, o estudo do conceito de inconsciente, a "psicologia das profundidades" (p. 86). E de Jung, o conceito de inconsciente coletivo (p. 87). A manobra teórica de Ramos é "assimilar o inconsciente interpsíquico", isto é, o inconsciente que "explica os fatos de intermentalidade, interpsicologia e psicologia das multidões", ao "inconsciente ancestral", englobando-os num conceito único, "inconsciente folclórico, que faz lembrar não só as influências ancestrais, como as que sobrem da massa gregária" (p. 88-9).

Vale dizer que Arthur Ramos era um leitor rigoroso e que caso tenha lido todos os autores que cita - etnólogos, antropólogos, psiquiatras e psicanalistas - com o mesmo afinco e competência com que leu Freud, então é possível afirmar que a combinação bastante original de autores presentes em seus livros deu origem a uma interpretação única do Brasil e dos brasileiros. ${ }^{1}$

Sua obra, marcada pelas múltiplas interlocuções possíveis entre psicanálise, psicopatologia e antropologia, não se resume a uma reflexão sobre a emergência do primitivo em cada ser marcado pela cultura. Trata-se, sim, de um verdadeiro painel teórico e etnográfico que apresenta uma visão inovadora sobre a constituição de nossas formas de subjetivação.

\section{Referências}

CAmpos, M. J. Arthur Ramos: luz e sombra na antropologia brasileira: uma versão da democracia racial no Brasil nas décadas de 1930 e 1940. Rio de Janeiro: Biblioteca Nacional, 2004.

Dalgalarrondo, P.; Gutman, G. e Oda, A.M.G.R. Osório Cesar e Roger Bastide: as relações entre arte, religião e psicopatologia. Revista Latinoamericana de Psicopatologia Fundamental, São Paulo, v. X, n. 1, p. 101-117, mar./2007.

1. No momento, estamos trabalhando sobre toda a extensão da obra de Arthur Ramos, em especial suas elaborações sobre "o negro brasileiro". Este trabalho tem a publicação programada para o número de dezembro da Revista Latinoamericana de Psicopatologia Fundamental. 


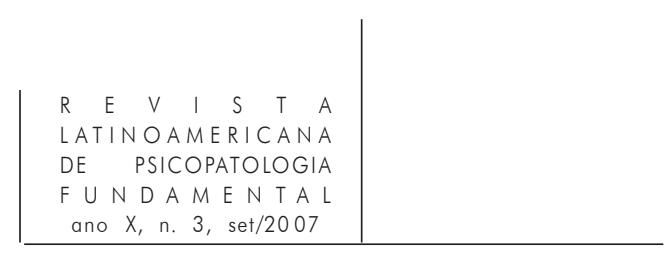

Gutman, G. O etnógrafo da mente. Revista Viver Mente e Cérebro, n. 175, p. 28-30, 2007.

Menezes, M. O. A psicanálise na Bahia (1926-1937): os estudos de Arthur Ramos sobre a loucura, educação infantil e cultura. 2002. Dissertação (mestrado em Ensino, Filosofia e História das Ciências), Universidade Federal da Bahia e Universidade Estadual de Feira de Santana. p. 56-63.

ODA, A.M.G.R. Nina Rodrigues e a loucura epidêmica de Canudos. Revista Latinoamericana de Psicopatologia Fundamental, São Paulo, v. III, n. 2, p. 139-144, mar./2000.

A teoria da degenerescência na fundação da psiquiatria brasileira: contraposição entre Raimundo Nina Rodrigues e Juliano Moreira. Psychiatry On Line Brazil, v. 6, dez./2001.

Ramos, A. Freud, Adler, Jung. Rio de Janeiro: Ed. Guanabara, 1933a.

Psiquiatria e Psicanálise. Rio de Janeiro: Ed. Guanabara, 1933b.

Educação e Psicanálise. São Paulo: Nacional, 1934.

1935.

O folclore negro do Brasil: demopsicologia e psicanálise. Rio de Janeiro: CEB,

Introdução à Psicologia Social. Rio de Janeiro: CEB, 1936.

Loucura e crime. Porto Alegre: Globo, 1937.

A criança problema. Rio de Janeiro: CEB, 1939.

SCHREINER, A. Uma aventura para o amanhã. Arthur Ramos e a neuro-higiene infantil na década de 1930. In: Duarte, L. F. D., Russo, J. e VenÂncio, A. T. A. (orgs.). Psicologização no Brasil: atores e autores, Rio de Janeiro: Contra capa, 2005.

SIRCILLI, F. Arthur Ramos e Anísio Teixeira na década de 1930. PAIDÉIA [USP], Ribeirão Preto, v. 15, n. 31, p. 185-193, maio-ago./2005.

\section{Resumos}

El psiquiatra brasileño Arthur Ramos da continuidad a la tradición de un abordaje antropológico y cultural de los fenómenos psicopatológicos iniciada por Raimundo Nina Rodrigues. En primera mitad del siglo XX, Ramos estudia el fenómeno de la locura a través de una interlocución con el psicoanálisis y con la antropología. Su aporte se sitúa más allá del referencial estrictamente psicopatológico, permitiendo también una interrogación fecunda de los procesos de subjetivación propios a los contextos culturales brasileños, sobretodo el de los pobres y los negros.

Palabras claves: Psicopatología, locura, psicoanálisis, antropología, cultura 


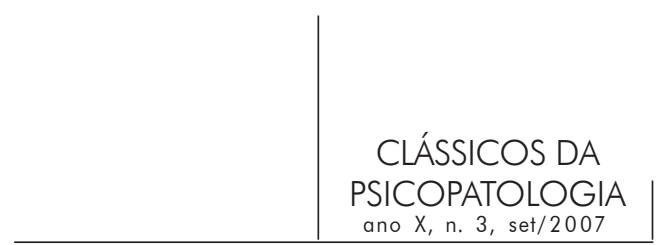

Le psychiatre brésilien Arthur Ramos donne suite à la tradition de l'approche anthropologique et culturelle des phénomènes psychopathologiques crée par Raimundo Nina Rodrigues. Dans la première moitié du XX $X^{e}$ siècle, Ramos étudie le phénomène de la folie à partir d'une interlocution avec la psychanalyse et l'anthropologie. Sa contribution va bien au-delà du point de vue strictement psychopathologique, permettant aussi l'interrogation féconde sur les processus de subjectivation propres aux contextes culturels brésiliens, surtout celui des pauvres et des noires.

Mots clés: Psychopathologie, folie, psychanalyse, anthropologie, culture

The Brazilian psychiatrist Arthur Ramos carries on the tradition of an anthropological and cultural approach to psychopathological phenomena, begun by Raimundo Nina Rodrigues. During the first half of the 20th century, Ramos studied the phenomenon of madness by employing an interlocution with both psychoanalysis and anthropology. His contribution consists of more than a strictly psychopathological frame of reference. It also allows readers to question more deeply the processes of subjectivation proper to Brazilian cultural contexts, especially those of the poor and the black populations.

Key words: Psychopathology, madness, psychoanalysis, anthropology, culture

Versão inicial recebida em julho de 2007

Aprovado para publicação em agosto de 2007 